OPEN ACCESS

Edited by:

Monika Akbar,

The University of Texas at El Paso,

United States

Reviewed by:

Yi Jin,

Kennesaw State University,

United States

Javier Rodriguez Moreno,

University of Jaén, Spain

Ana Maria Ortiz Colon,

University of Jaén, Spain

*Correspondence:

Chi-Yang Chung nu10177@gmail.com

Specialty section: This article was submitted to Digital Education,

a section of the journal

Frontiers in Education

Received: 26 August 2021 Accepted: 03 February 2022 Published: 24 February 2022

Citation:

Lee $\mathrm{H}-\mathrm{Y}$, Chung $\mathrm{C}-\mathrm{Y}$ and Wei $\mathrm{G}$ (2022) Research on Technological Pedagogical and Content Knowledge: A Bibliometric Analysis From 2011 to 2020. Front. Educ. 7:765233.

doi: 10.3389/feduc.2022.765233

\section{Research on Technological Pedagogical and Content Knowledge: A Bibliometric Analysis From 2011 to 2020}

\author{
Hung-Ying Lee ${ }^{1}$, Chi-Yang Chung ${ }^{2 *}$ and Ge Wei ${ }^{3}$ \\ ${ }^{1}$ Department of Physical Education and Sport Sciences, National Taiwan Normal University, Taipei, Taiwan, ${ }^{2}$ College of \\ Education, Jinggangshan University, Jiangxi, China, ${ }^{3}$ College of Elementary Education, Capital Normal University, Beijing, \\ China
}

This study was to explore the bibliometric characteristics of TPACK from 2011 to 2020. By using the keyword "TPACK," the bibliographic references have been retrieved from the Scopus databases (date of search: March 7, 2021). The VOSviewr software tool and Bibliometrix $\mathrm{R}$ package were used for information analysis. The results confirmed that there are 700 articles, representing 63 countries and 159 journals scanned. Articles in 2013 were cited the most times, and since 2016, the number of articles is on the rise every year. The United States, Turkey, and Australia were the three leading countries in this field. Most of the articles were published in educational technology journals. The total articles published by American institutions are more than the others, followed by Asian institutions. The most prolific authors are all Asians, followed by Americans. Core themes from the highly cited articles have been surrounding PCK, teacher education, skill, and pedagogy. The development of TPACK has gradually turned to practical strategies and tried to find strategic ways to facilitate teachers to implement technology-assisted teaching.

Keywords: bibliometric analysis, TPACK, technology, teacher education, in-service teacher, pre-service teacher, quantitative

\section{INTRODUCTION}

Many educational studies have proved the effectiveness of technology-assisted teaching in recent years as a result of the advancement of information technology (Herold, 2016). Educational technology can help students learn more effectively, but successfully integrating it into the teaching of specific courses is a challenging task (Herring et al., 2016; Yeh et al., 2021). Mishra and Koehler (2006) built on Shulman's pioneering work by claiming that teachers should create a complex, situated, and integrated body of knowledge known as technological pedagogical and content knowledge (TPACK). As a result, teachers' professional knowledge of TPACK has been discussed regularly. This includes academic perspectives as well as teaching practices.

The TPACK framework has grown in popularity in the school as well as in research, as evidenced by the fact that the TPACK framework is used in over 471 journal articles on the Web of Science (Soler-Costa et al., 2021). The TPACK is a theoretical framework that focuses on how technology is integrated into teaching by providing a holistic view of the entire knowledge base teachers need to understand to effectively apply technology in teaching, it may have a significant impact. 
However, Graham (2011), the distinction between the three parts is sometimes fuzzy, their interaction with one another needs to be clarified, and its utility in predicting important outcomes is questionable. Therefore, the TPACK framework has seen various modifications over the last 15 years. Scholars and researchers use the current framework to define and discuss technologyenhanced instruction.

In researchers' conceptualization, some researchers have emphasized specific technologies (e.g., TPCK-W for the World Wide Web; Lee and Tsai, 2010) and G-TPACK for geospatial (geographic) technologies (Doering et al., 2014). Other researchers have developed TPACK conceptualizations such as the TPCK framework, the TPACK-Practical framework, the ICT-PCK framework, and the TPACK-SAMR framework as different ways of visualizing the knowledge domains and how they interact with one another (Angeli and Valanides, 2005; Porras-Hernández and Salinas-Amescua, 2013; Yeh et al., 2014; Tunjera and Chigona, 2020).

As can be seen from the development of the TPACK model described above, this is a rapidly developing field of knowledge. A Google search for "technological pedagogical content knowledge" provides over 14,100,000 results, whereas a Google Scholar search for "articles" produces around 978,000 results. The growth of the use of the TPACK framework by researchers has also been explored in published reviews of the literature (Foulger et al., 2021; Yeh et al., 2021) that speak to the proliferation of the use of the TPACK framework by scholars.

From the above point of view, it shows that with the rapid development of academic publishing in recent years, researchers and educators are unable to grasp the knowledge structure in this field quickly. Previously, Rosenberg and Koehler (2015), Wang et al. (2018), and Willermark (2018) are all conducted review studies on TPACK. In addition to the discussion on the practical level, further discussion and continuous tracking of the framework are also needed. "TPACK-a review of the literature" by Voogt et al. (2013) is the most referenced Scopus article in the last 10 years. It is worth mentioning that the study is a review of 20052011, and the study suggests also show that follow-up research can be followed continuously to promote the mastering of the complex TPACK model. As a result, a current and systematic synthesis of the research is needed since the framework continues to attract attention across the educational field, as indicated by the increasing number of publications that refer to TPACK.

Although there have been a variety of literature review methods in recent years, the methods of analysis are also different due to different themes and purposes. Owen et al. (2014) suggested that when more variables need to be explored in the future, a more extensive and comprehensive analysis method can be used to summarize more samples (journal articles) to facilitate the mastery of Knowledge development in the field. From the above-mentioned TPACK-related research, it can be seen that much literature is drawn from different angles, and the literature in this field has signs of rapid development. Due to the rapid increase in the number of academic publications in recent years, it is difficult for researchers to keep abreast of the latest academic trends and keep up to date with the latest knowledge (Briner and Denyer, 2012).
However, because academic journals are the main channel for disseminating knowledge, based on the same concept mentioned above, bibliometrics has gradually become an important part of research methodology.

In addition to helping researchers track updates of literature and research models, bibliometrics can also provide researchers with metrics, preferences, and trends in academic publications. More notably, bibliometrics presents a bigger picture to help researchers grasp the knowledge structure of the field. Therefore, this study employs bibliometric characteristics to follow the development of the TPACK model. As previously stated, the importance of the TPACK model for technologyassisted teaching and learning is obvious, and it is rapidly developing. This research aims to demonstrate the model's relevance by analyzing at co-occurrence in bibliographic data in the Scopus database, as well as to provide a concrete framework for research and a structural diagram for the framework.

\section{LITERATURE REVIEW}

\section{Technological Pedagogical and Content Knowledge Framework}

Advocated by Shulman (1987) Pedagogical Content Knowledge (PCK) indicates that teachers should have Content Knowledge for pedagogy to understand the level and ability of students, solve and analyze students' learning difficulties and problems, and improve the teaching effect (Shulman, 1987). PCK can provide teachers with professional knowledge and ability in teaching. Nonetheless, to keep up with the rapid advancements in information technology, teaching and learning must adapt to changing times. From Shulman's theory, PCK does not show the relationship between technology, instruction, and learners, nor how teachers may assist learners to use technology to transform knowledge.

Shulman's (1986) characterization of teacher knowledge was extended by Mishra and Koehler's (2006) development of the technological, pedagogical, and content knowledge (TPACK) framework, which explicitly considered the role that technology knowledge might play in effective teaching. Specifically, three major knowledge components form the foundation of the TPACK framework include, including Content knowledge (CK), Pedagogical Knowledge (PK), and Technological Knowledge (TK).

In addition, the TPACK framework has four components that address how these three bodies of knowledge interact, restrict, and afford each other, as follows: Technological Content Knowledge (TCK) refers to knowledge of the reciprocal relationship between technology and content. Disciplinary knowledge is often defined and constrained by technologies and their representational and functional capabilities. PCK is to Shulman's (1986) notion of “an understanding of how particular topics, problems, or issues are organized, represented, and adapted to the diverse interests and abilities of learners, and presented for instruction" (p. 8). Technological Pedagogical Knowledge (TCK) refers to an understanding of technology 
that can constrain and afford specific pedagogical practices. Technological Pedagogical Content Knowledge (TPACK) refers to knowledge about the complex relations among technology, pedagogy, and content that enable teachers to develop appropriate and context-specific teaching strategies (Mishra and Koehler, 2006).

TPACK is a beneficial conceptual framework for thinking about, analyzing, and assessing what educators need to know to integrate technology into their classrooms, but it must ultimately be viewed as a framework for how teachers can best create this integrated knowledge (Koehler et al., 2014). Over the past decade, TPACK's model framework is constantly being implemented in research related to teaching technology or technology-assisted teaching with the advancement of information technology (Hilton, 2016). When it comes to designing instruction, researchers have emphasized the importance of teachers having a strong conceptual knowledge of the interactions that occur between technology, pedagogy, and content (Harris and Hofer, 2011). Some go through to explain how this understanding might lead to more successful classroom teaching (Hughes, 2005; Niess, 2005). The integrated knowledge domains (such as TCK, TPK, PCK, and TPACK) are highlighted to give a model that depicts the complexity of the multiple lenses of teacher knowledge that is required to comprehend and define this framework.

Some researchers have emphasized the value of TPACK in teacher practices such as lesson planning (Harris and Hofer, 2011) or practical teaching (TPACK-P) (Lux et al., 2011; Yeh et al., 2014). TPACK has repeatedly been viewed as a kind of knowledge that is resident in the heads of individual teachers, as Di Blas et al. (2014) have pointed out TPACK scholars have recently begun to advocate for a more distributive and contextual understanding of TPACK, conceiving it as a type of knowledge shared by members of a teaching community (Di Blas and Paolini, 2016; Carpenter et al., 2020).

However, Schmid et al. (2020) show the majority of TPACK studies was not considered the realm of context knowledge. Although context has been conceptualized as a relevant body of knowledge (Mishra, 2019) only a few studies have made empirical efforts to investigate it as an additional component of teachers' knowledge (Jang and Tsai, 2012). In addition to the lack of references to contextual factors, another consideration regarding the content of the instrument may be that assessing TPACK at the level of teaching subject could be a too broad approach given that knowledge may vary across topics (Schmid et al., 2020). Therefore, this study will use the big picture method of bibliometrics to discover the TPACK model's knowledge structure in the field and important themes.

\section{Bibliometric Methods}

Researchers have found it challenging to keep up with the latest trends and update their knowledge due to the significant increase in the number of academic publications in recent years (Briner and Denyer, 2012). Academic journals are the primary means by which knowledge is transmitted, and "Bibliometrics" is becoming an increasingly important component of research methodology. The use of mathematical and statistical methods in books and other media was originally defined as bibliometric (Pritchard, 1969; Abramo and D'Angelo, 2011). Unique variables, cocitation links, relevant topics, co-occurrence, and co-authorship, keywords, publication countries, organizations, and the effect of specific articles, journals, and authors may all be classified and presented using bibliometrics (Ryan and Woodall, 2005; De Battisti et al., 2015).

Simple methods are used to organize the current data on a group of study objects. More complex techniques can also be used to create, visualize, and explore maps based on network data (Tsay, 2011; Hung, 2012; Kevin et al., 2017). This type of analysis not only helps researchers analyze the evolution of literature and research models, but also provides productivity metrics as well as research goals and publication preferences (Hussain et al., 2011). Furthermore, bibliometric map analysis software such as VOSviewer, a program for building and examining bibliometric maps (Van Eck and Waltman, 2010, 2017), has arisen, which is characterized by a simple and thorough grouping of subjects.

Co-citation analysis, on the other hand, is a variation of normal citation analysis (Zupic and Čater, 2015). It's a pioneer in the field of bibliometrics, defined co-citation as the frequency with which two units (e.g., authors, documents, journals) are cited together (Small, 1973; Cobo et al., 2011). Co-citation can also be used to explain hot trends and is commonly used in computer science, information science, and medicine (Chen, 2006). In the current research, bibliometric visualizing methods have been applied through VOSviewer to visualize further analysis results. It defined co-citation as the frequency with which two units (e.g., authors, documents, journals) are referenced together (Small, 1973). It is a pioneer in the field of bibliometrics. Co-citation is extensively used in computer science, information science, and medicine to explain current events (Chen, 2006). To visualize the results of the current study, bibliometric visualizing approaches were used in combination with VOSviewer.

This study employs bibliometric analysis methods in conjunction with various types of bibliographic data to conduct a big-picture analysis to comprehend the knowledge domains of TPACK. In addition, long-term research results (2011-2020) based on academic citations can indicate subsequent research directions and elucidate the current research network regarding information technology education, allowing researchers to identify global research trends in TPACK. According to Scopus, more than 1,000 articles have been published in the TPACK field in the past decade. However, bibliometric analysis is used in only a few TPACK research. Determine the knowledge structure of this topic and potential research goals. The following are some related research questions:

(1) What is the status of annual publications for 2010-2020?

(2) Which countries are the 10 countries with the most publications?

(3) What are the top 10 journals that published most TPACK research?

(4) Who are the 10 most frequently published authors?

(5) What are the co-occurrences that were explored on TPACK research? 


\section{MATERIALS AND METHODS}

\section{Ethics Statement}

This study was a retrospective bibliometric analysis focusing on analyzing the published articles. No clinical trials were conducted in this study. Approval from an institutional review board was not applicable.

\section{Study Design}

It is a bibliometric examination of a specific topic based on the Scopus literature databases. Based on the bibliometric methodology literature, Zupic and Čater (2015) offered process guidelines for science mapping analysis using bibliometric methodologies. For the five-step approach for doing science mapping, the authors followed the preferred reporting items that included study design, data collection, data analysis, data visualization, and interpretation.

\section{Data Collection}

Data related to the present study were retrieved from Scopus on March 7, 2021. one term "TPACK" was used as the keyword for searching journal articles. Only those publications published in the years ranging from 2011 to 2020 were considered to retrieve related data from the past. In line with the main purpose of identifying this research, Scopus is selected as the database for the following bibliometric analysis. In this manner, we searched 1,210 articles in total. After manual coding, we removed 484 articles that did not target TPACK or not articles first. Second, we removed 26 articles not published in English. Finally, there are 700 articles were selected for the subsequent analysis.

\section{Data Analysis}

To begin, bibliographic data for 700 publications were acquired from the Scopus website and saved as.csv (comma-separated values) files. The saved data contained author names, organizations, article titles, keywords, abstracts, and various citation data. A copy of the.csv file with the identical information was also stored in Excel. Second, the data collected from the Scopus database were imported into VOSviewer software and Bibliometrix R package to draw a network map and visualize it.

\section{Visualization}

A bibliographic visualization tool was created by Leiden University's center for science and technology studies (CWTS). The correlation strength of measurement was used to evaluate network visualization, overlay visualization, and density visualization of cluster normalization (Van Eck and Waltman, 2010). The web of science, Scopus, PubMed, and RIS databases are among the file types that can be analyzed. Author relationship, keyword co-occurrence, citation, and literature coupling are examples of analytical types. VOSviewer is a useful tool for mapping scientific information, and it's well suited to displaying big bibliometric maps. The maps are very simple to understand (Van Eck and Waltman, 2017).

When using VOSviewer to process data, the software will examine the items based on their frequency of occurrence or threshold size. The data will be too huge if the threshold is set too low; otherwise, the data will be too sparse. As a result, the author will establish the visualization map size barrier based on readability and literature analysis. The Bibliometrix $\mathrm{R}$ package is a one-of-a-kind resource for quantitative bibliometrics and scientometrics research. It's written in $\mathrm{R}$, which is a free and open-source programming language (Aria and Cuccurullo, 2017). It's easy to simplify analyses and add new functions in $\mathrm{R}$ because it's an object-oriented and functional programming language.

\section{Interpretation}

The results of the bibliometric study must be interpreted as the final step. However, it must be careful not to try to match the study to their preconceptions, but rather to apply their knowledge to improve the findings. Because bibliometric methodologies frequently depict the essence of a field differently than traditional literature evaluations, these disparities must be reconciled. In this type of academic document, the structure is highlighted. The goal is to explore how structural aspects (groups of publications, authors, and concepts) link and influence one another, as well as their role in the study field's substantive problems.

\section{RESULTS}

\section{Annual Publications}

As shown in Figure 1, 41 articles were published in 20112012. Although the number of publications in 2011-2012 is relatively small compared with the following years, perhaps this is also a stage of professional knowledge being developed and discussed. It rose sharply in 2013, total publications increased to 75 , and maintained above 60 articles every year, except in 2014. Since 2019, the number of annual publications has exceeded 100 and continues to increase. In addition, more articles in 2013 were cited, up to 2,081 times. It is because, in 2013, a large number of empirical studies and literature reviews on TPACK were published. It also created a crucial foundation for future TPACK research.

\section{Publications Countries}

A total of 63 countries were counted and only the top 10 countries were listed. The top 10 countries were presented in Figure 2. The United States had the most publications, the second is Turkey, and the third was in Australia, and these three leading countries constituted $51 \%$ of the total 701 articles. In addition, the number of publications in the United States far surpasses other countries, and it is the leading country in the research field of TPACK. However, it is worth noting that among the top 10 countries, there are many Asian countries, which also means that Asian countries have a lot of research on TPACK issues, and even have collaboration in research.

This study also shows the network visualization of various countries through Figure 3. There are strings of countries in the figure, which indicate that authors maybe collaborate research or cite each other's articles. The wider the circle, the more 

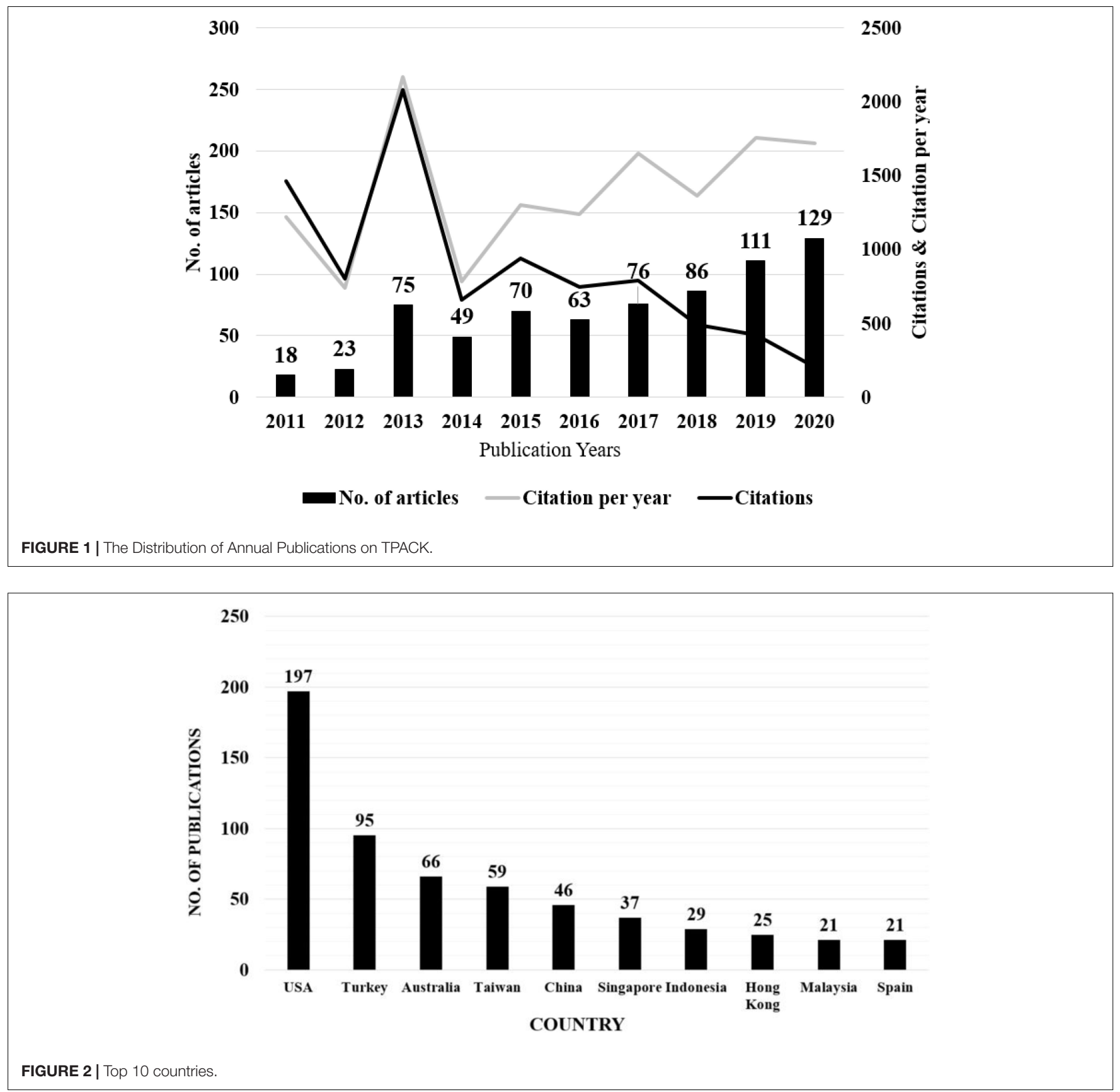

publications there are, the thicker the lines connecting them, and the closer the association. The United States is in the middle of the picture that is because the author who proposed the original framework of TPACK is from the United States. As a result, relative follow-up research will cite this paper, which also establishes the United States as a major point, influencing the publication status of multiple countries. The United States interacts more with Asian countries, as can be seen in the image. Furthermore, the four green Asian countries have collaborated and been cited numerous times. There could be two explanations for this. The first is that their points of view and concepts are the same. The second reason could be due to Asia. It is because the cultures are so similar that compared international in-service teachers with pre-service teachers.

\section{Publications Journals}

The top 10 most-publication journals are shown in Figure 4. The top five are Computers and Education (32), Education and Information Technologies (28), Journal of Digital Learning in Teacher Education (28), Journal of Research on Technology in Education (27), and Australasian Journal of Educational Technology (24). Other journals also published at least 13 TPACK related articles, and Educational Technology Research, Development, Education and Information Technologies and 


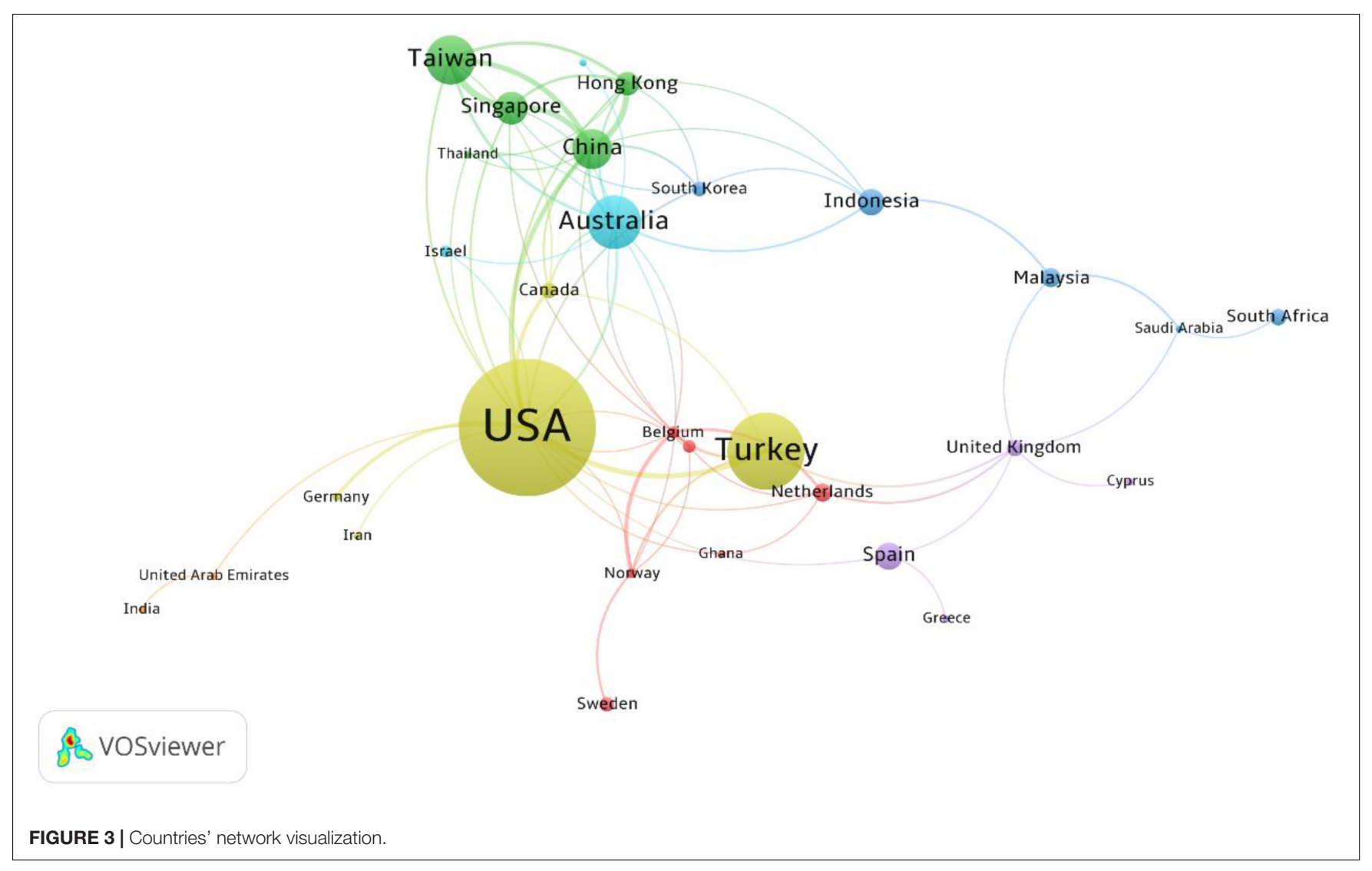

Australian Educational Computing are ranking 10ths. As can be seen in Figure 4, practically every top 10 journal contain the word Technology. Technology has extended throughout education, as evidenced by the journal's title. It even includes numerous journals in the field of social sciences citation index of education that have a high impact index, such as the number one Computers and Education, which has an impact factor of 5.30 and is a highly influential journal in social science education research.

\section{Publications Authors}

The top 10 most-publication authors in Figure 5. The top three are Chai, C.S. (35), Koh, J.H.L. (21), and Tsai, C. C. (16). In the density visualization of Figure 6, keywords densities calculated are translated into colors using a color scheme. By default, VOSviewer uses a red-green-blue color scheme. In this color scheme, red corresponds with the highest item density and blue corresponds with the lowest item density. Figure 6, shows the authors publishing most articles in TPACK related research. In addition to telling us who the experts and scholars of TPACK are, this result also highlights their importance and influence in this field. The hue is particularly dark on the right side of Figure 6 because scholars from Asian countries have published more than 10 studies on TPACK. What's more, it's worth noting, the network visualization of Figure 7 presents the relationship among the authors, including authors' citation relationship and co-authorships in TPACK research to demonstrate that the authors' research variables or opinions are similar. Professor
Ching Sing Chai of the Chinese University of Hong Kong's Department of Curriculum and Instruction is the largest and most published member of the circle. For a long time, he has been researching the development of various TPACK models and related scale verification research, as well as giving more new research for follow-up researchers in the field of educational research. Chai, C.S., Koh, J.H.L., Tsai, C. C., and Liang, J. C. have many collaborations and even attempt to break through the new form of the TPACK model. They have also talked about how college students and pre-service teachers in a variety of Asian countries feel about TPACK. It also introduces a slew of new education ideas to the professional topic.

\section{Co-occurrence}

In Figure 8, the lines represent the co-occurrence among those keywords and the size of each node indicates the number of documents, the larger the node the more documents co-occur. TPACK is the leading keyword and has stronger links with PCK, teacher education, skill, and pedagogy. As can be seen from the density visualization in Figure 8, in addition to the detection of relevant hot spots, it can also know which participants were found in these studies, and what research methods and analysis methods were used. It can be seen that most of the TPACK study is carried out through quantitative research. Figure 8 shows that it is mainly separated into two sections. The right-hand green one is mostly about research methodologies. The majority of them use quantitative analytical methods such as correlation, 


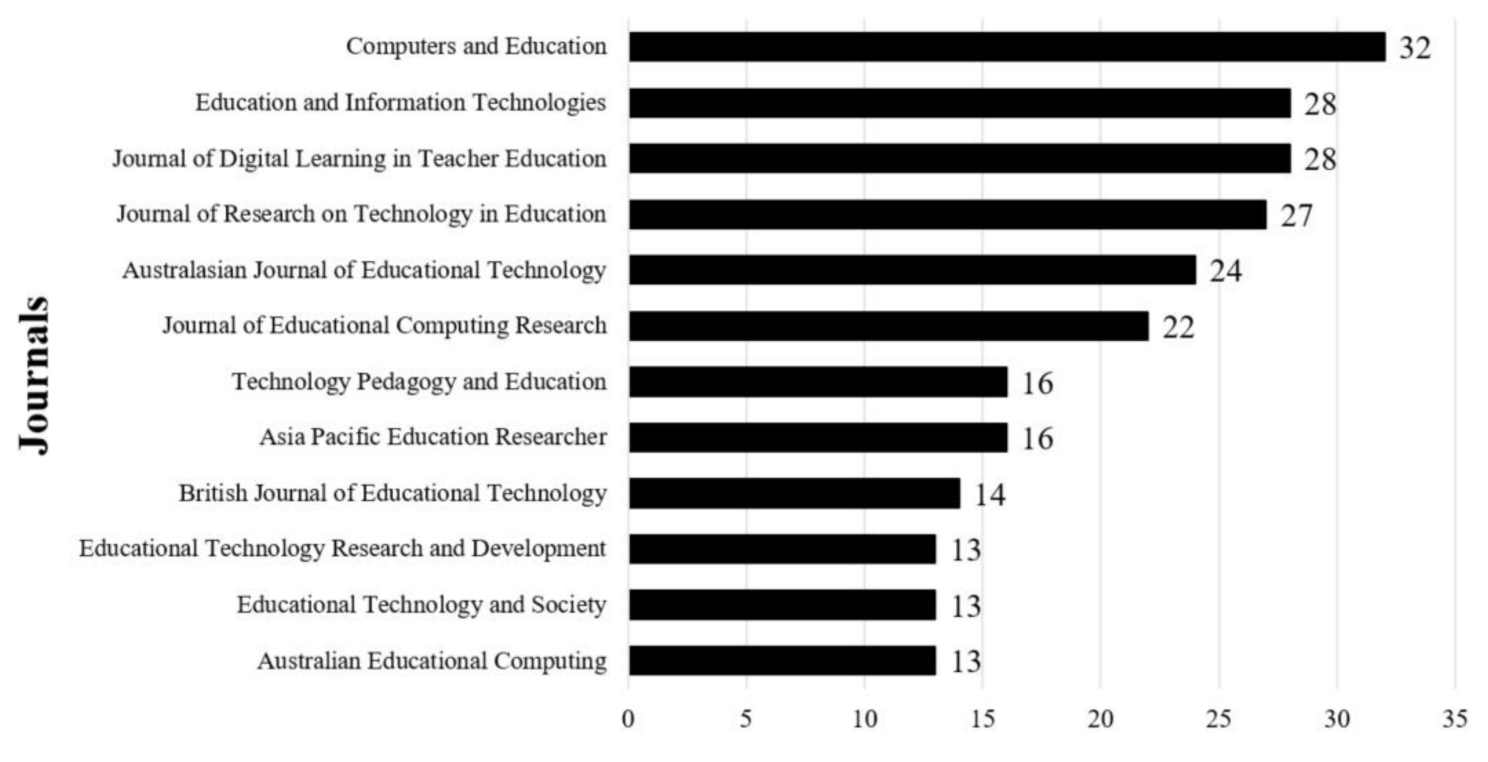

No. of Publications

FIGURE 4 | Top 10 leading journals with publications.

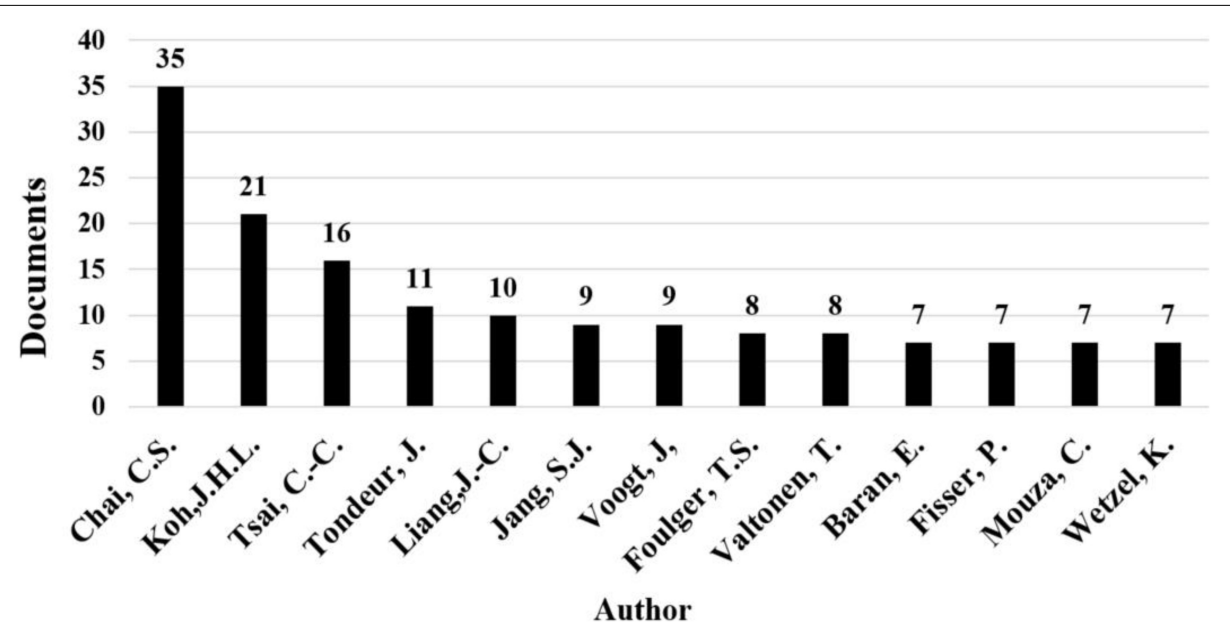

FIGURE 5 | Top 10 authors.

confirmatory factor analysis, and exploratory factor analysis. This is about survey instruments so that you can use them. There are additional terms connected to the questionnaire, such as item, factor, and dimension, as shown in Figure 8. It even looks into the questionnaire's reliability and validity after it has been measured.

The majority of them are variables related to teaching practice, as shown by the red on the left side of Figure 8. The design of the curriculum, the application of pedagogy, and the efficacy of students' learning are all factors to consider. TPACK primarily begins with the teacher's perspective, it will involve two major groups of educators. The first are in-service teachers who are already on the work and are in the course of their careers. Many research will explore teachers with various teaching experiences and levels to identify which kinds of teachers have TPACK Comparatively decent opinions or abilities. The second step is to examine teacher education programs. Pre-service teachers are still developing their professional knowledge, therefore they will need to prepare relevant knowledge and abilities as they enter the twenty-first century with sophisticated information technology.

Next, we refer to Cobo et al. (2011) identified a bibliometric approach that evaluates a research field and detects and visualizes its conceptual subdomains (specific topics/themes or general thematic areas) and thematic evolution using both performance analysis and science mapping tools. Using the Bibliometrix $\mathrm{R}$ package's functions, a research area can be viewed as a collection of research topics, mapped in a two-dimensional strategic 


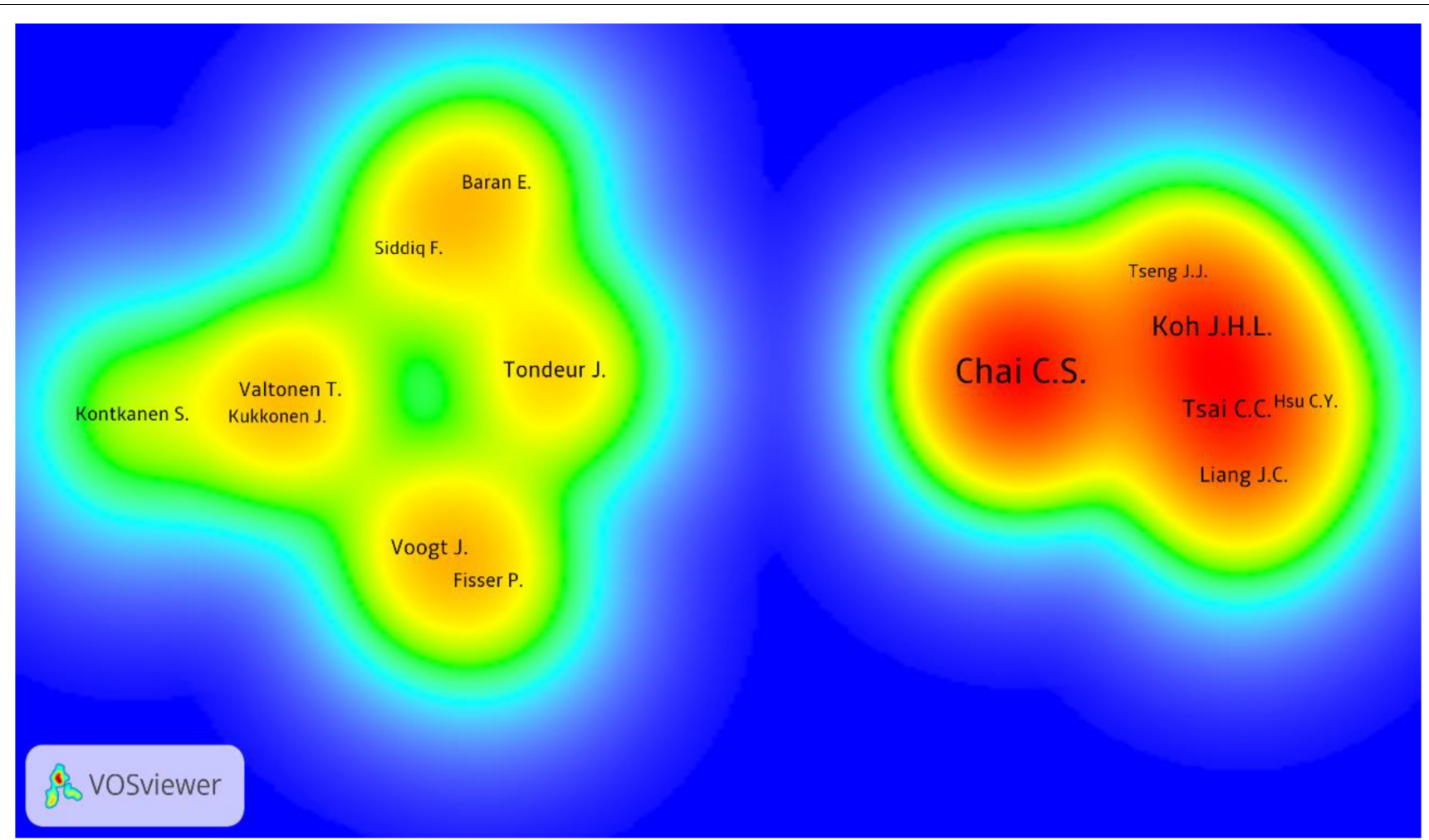

FIGURE 6 | Author's published density visualization.

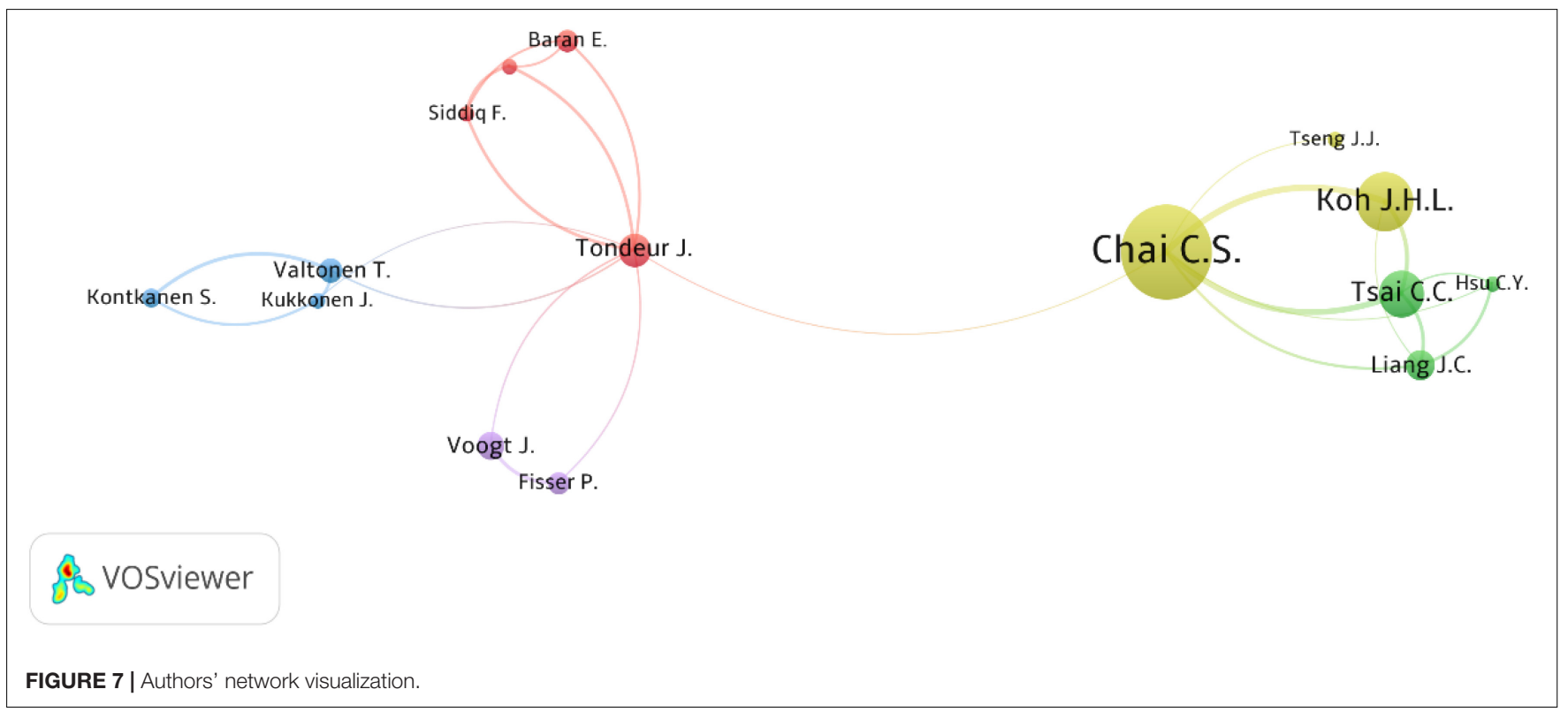

diagram (Figures 9, 10), and split into four categories: (a) Motor themes: Themes in the upper-right quadrant are well-developed and crucial to the structure of a research field. They are known as the specialty's motor themes because of their high centrality and density. (b) Niche themes: Themes in the upper-left quadrant have well-developed internal relationships but minimal exterior linkages, making them of just marginal regional significance. These are highly specialized and ancillary topics. (c) Emerging or declining themes: Themes in the lower-left quadrant are both marginal and underdeveloped. The themes in this quadrant have a low density and centrality, and they frequently reflect fresh or vanishing motifs. (d) Basic and transversal themes: Themes in the 

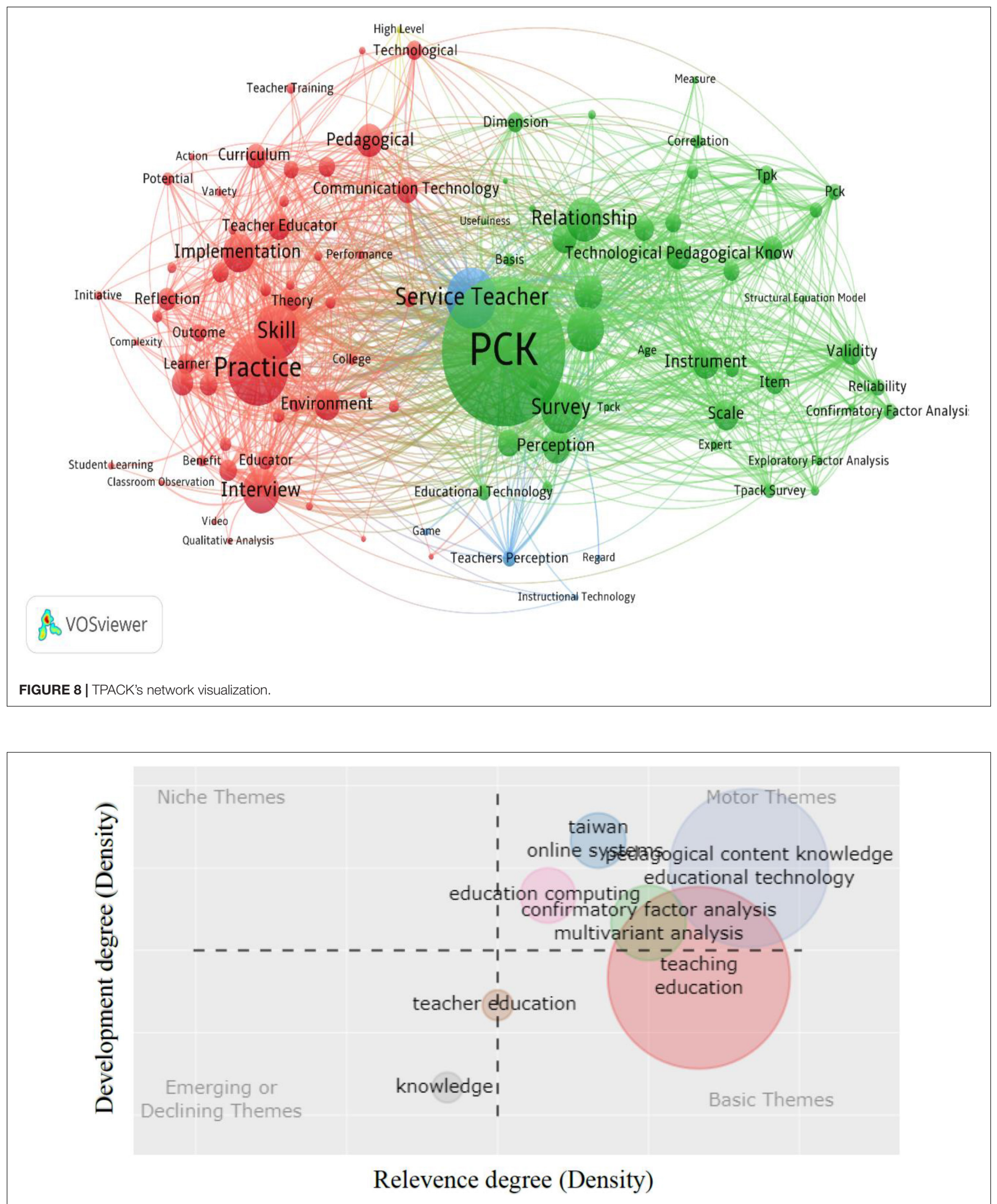

FIGURE 9 | Strategic diagram (2011-2015). 


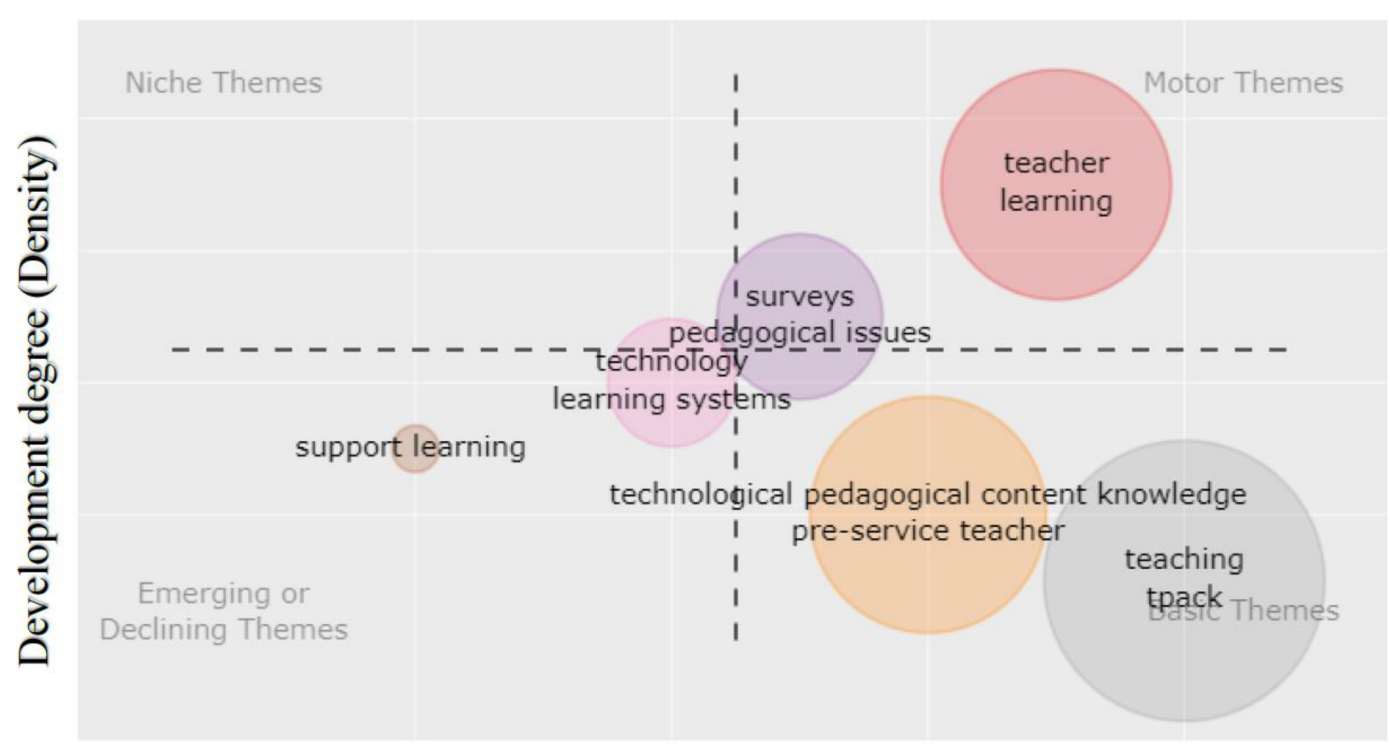

\section{Relevence degree (Density)}

FIGURE 10 | Strategic diagram (2016-2020).

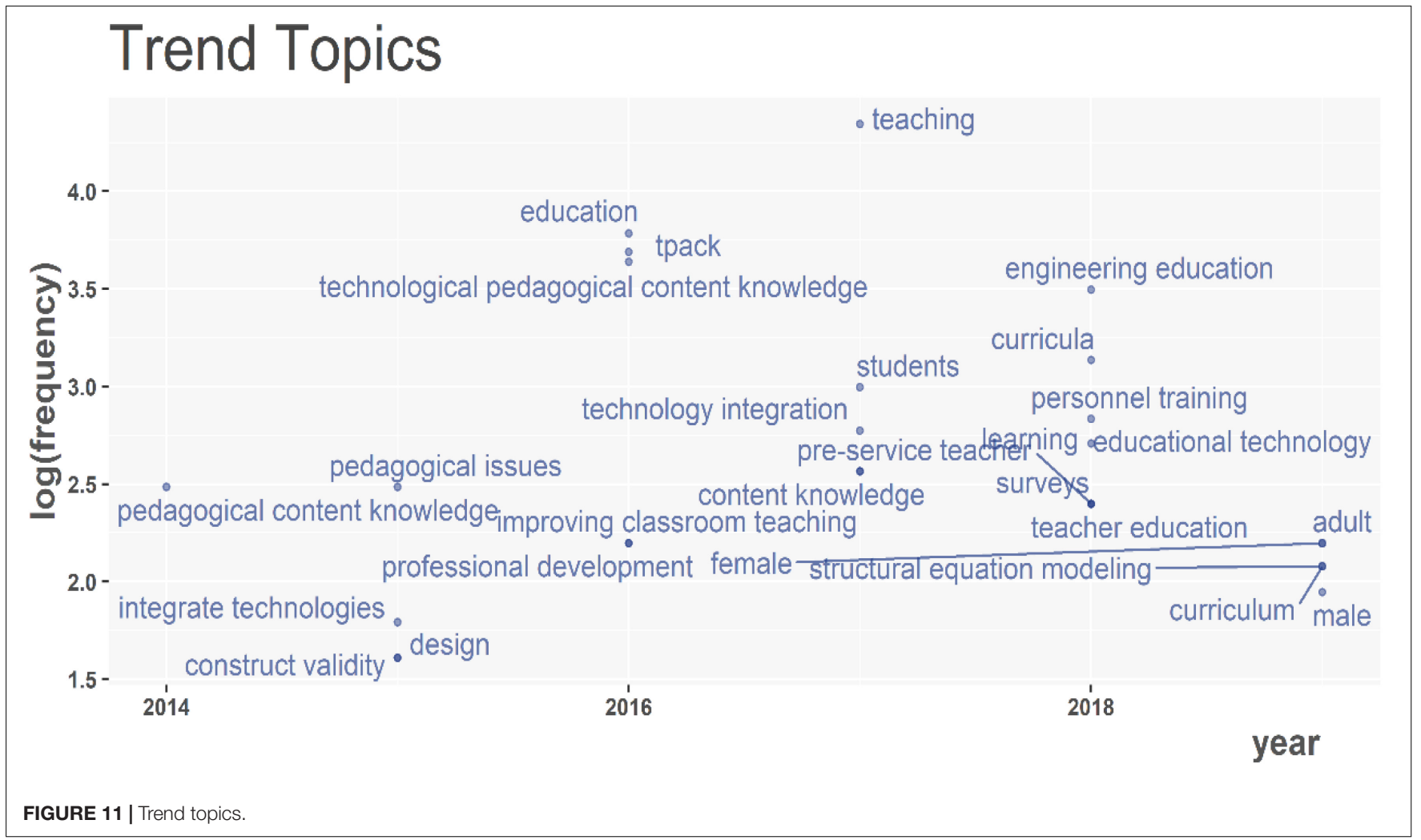

lower-right quadrant are important for a research topic, although they are still evolving. This quadrant contains both transversal and general themes.

To comprehend the changes and development context of its issues, we divided TPACK into the first 5 years and the next
5 years, as shown in Figures 9, 10. Since the previous 5 years were still in development, many issues were concentrated on the fundamental themes, as seen in the Strategic diagram in Figure 9. The publications discussed from the field of teacher education are also in the early stages of development, and the 
majority of them employ questionnaires to assess pre-service teachers' perceptions and have not yet delved into specific training methods and strategies.

However, based on the content of the preceding Figure 1, it is clear that the number of papers published in the recent 5 years will be significantly more than 2011-2015, and will continue to rise year after year. Therefore, the variety of TPACK in the field of education, you can also see the major differences between Figures 9, 10 are shown. The transfer of teacher learning from basic to motor themes, for example, demonstrates that numerous articles have been written about the professional development of educators and practitioners that need continuing to improve. Furthermore, there are no niche theme variables between the first 5 years and the next 5 years. It is well recognized that the topics covered by TPACK are more focused than those covered by other educational topics. The research methods, research participants, and research topics have all been narrowed down. It's worth noting that support learning and teacher learning, which includes pre-service and in-service teachers, is currently the most important topics of TPACK, as shown in Figure 10. Due to the rapid development of information and technology, many types of research on technology in teaching have clarified its effectiveness. As a result, a growing number of teachers have recognized the necessity for professional training in technological knowledge to understand how to integrate TPACK.

We know that in recent years, more and more articles have examined how to strategically improve teachers' TPACK, which encompasses both in-service and pre-service instructors, from Emerging or declining themes. This may lead to the next TPACK development. Some publications have even begun to invest in qualitative research observations or interviews to better understand the state of instructors' learning and usage of technology, to gain a better understanding of the professional knowledge learning process. This is also in line with the state of Figure 11 in terms of Trend themes. From the simple talk of PCK to the changes after TPACK intervention, and then progressively to the specific practice of implementation, that can be seen. Trend topics also show that there has been a gradual issue been discussion increase in the last 2 years, especially courses for training and professional growth. This could also give TPACK a renewed chance at growth, allowing it to progress even further.

\section{DISCUSSION AND CONCLUSION}

TPACK's core themes from the highly cited articles have been surrounding PCK, teacher education, skill, and pedagogy. First and foremost, the section regarding PCK in this study contains both TPACK and PCK. The amount of study into TPACK has expanded rapidly in recent decades, resulting in rapid changes in knowledge in this field (Willermark, 2018). Self-assessment through questionnaires was the most commonly utilized method for examining TPACK. Participants were frequently asked to assess items quantitatively on a 5- or 7-point Likert scale, with subscales measuring all seven or a subset of the TPACK knowledge domains (Schmidt et al., 2009; Chai et al., 2013). The questions were of a generic type, focusing on what teachers believed they understood, regardless of context. Several instruments have been created that use various methods to operationalize the TPACK construct.

In addition, TPACK includes seven knowledge dimensions that are well known, and the majority of the study focuses on the four high-level knowledge dimensions of PCK, TCK, TPK, and TPCK. Some researchers have viewed TPACK as an extension of PCK (Niess, 2005), while others have viewed it as a distinct category of knowledge (Angeli and Valanides, 2009; Cox and Graham, 2009). Therefore, we can deduce that the quick release of TPACK includes discussions of various knowledge concepts. This provides a field with new challenges and stimulation, as well as a degree of uncertainty about the original framework. Even a large number of studies may aid TPACK in obtaining a more diverse perspective. Continuously update the knowledge structure of this field to clarify the knowledge of the next generation of teachers.

The main research participants are educators, including inservice teachers and pre-service teachers. The results of these two main research participants can also be discussed together with the skills shown in Figure 8 of this research. For pre-service teachers, most of the past research has been conducted through self-report measures, interviews, performance assessments, openended questionnaires, and observations (Wang et al., 2018). It's also worth noting that preservice teachers are more likely to repeat the same type of technology integration activity they learned in their previous classrooms (JaipalJamani and Figg, 2015), demonstrating the value of technology modeling and how strategically scaffolding those experiences throughout a preparation program can influence preservice teachers' development of TPACK. In previous research, the first iteration of studies using questionnaires focused primarily on "general" preservice teachers' development of TPACK (Schmidt et al., 2009), whereas the second iteration of studies using questionnaires focused more on subject-specific preservice teacher knowledge development related to TPACK (Özgün-Koca et al., 2010; Lin et al., 2013). The research trends indicate an increased interest in TPACK research over time (Wu, 2013). The highest number of TPACK articles was found in educational technology journals, which is aligned with the results reported by Chai et al. (2013).

However, studies still mainly focus on examining teacher TPACK from the perspective of knowledge rather than competence. This can be problematic as gaps have been shown to occur between self-reporting and performance in practice, between displayed knowledge and application of such knowledge, and between performance exercises and typical behavior (Willermark, 2018). This is also supported by the findings of Figures 9, 10 of this study. Teacher education research began with a study of pre-service teacher knowledge development. It has, however, gradually shifted in recent years to explore more specific subject knowledge. This demonstrates that teacher education is using the TPACK implementation strategy to better identify teachers' knowledge levels. Identifying teacher TPACK through teaching activities has several advantages. Teachers must use their knowledge in real-world situations when using this approach. Studying planning activity performance is beneficial because it captures teachers' pedagogical reasoning, 
intents, and decision-making about how to connect learning goals with pedagogical tactics, as well as their tool selection and use (Willermark, 2018).

For in-service teachers, teachers' professional knowledge may become the main focus as it has been proved to be a key predictor of instructional quality, teachers' professional knowledge may become the main focus (Baumert et al., 2010). There are generic frameworks that address necessary knowledge in the context of digital transformation (Van Laar et al., 2017; Oberländer et al., 2020). Teachers with different teaching years and experience transfer and implement knowledge in different ways. As a result, various workshops and projects have been conducted to promote the professional development of in-service teachers' TPACK (Tseng and Kuo, 2014; Yurtseven Avci et al., 2020). It even promotes the development of Self-regulated learning for TPACK through a computer-based learning environment (Huang and Lajoie, 2021; Huang et al., 2021). At the moment, teacher training looking for a good strategy to help teachers enhance their TPACK, which might involve using teaching consultation or one-toone faculty support methods to help teachers develop unique professional knowledge (Koh, 2020).

For specific teaching strategies, TPACK-SAMR Models is a new-style way to review and evaluate the application value of technological tools (Tunjera and Chigona, 2020). SAMR Models include the following four main stages, substitution, augmentation, modification, redefinition. SAMR Models assist teachers in effectively using technology and integrating it into classroom teaching and provide a framework to support teachers and course designers to use mobile devices to create the best and most suitable learning experience. This model encourages teachers to integrate low-level technology into teaching, and then gradually use high-level technology to integrate into teaching to promote teaching and learning to a higher level. When used together, the TPACK and SAMR models provide important insight into where obstacles and opportunities arise when selecting technology for student learning (Drugova et al., 2021). TPACK helps teachers contextualize the information they need to integrate technology. SAMR supports the analysis of the precise levels used for enhancement and transformation, as well as the examination of integration from both the teachers' and students' perspectives (Kihoza et al., 2016). It can be seen that TPACK training has gradually found more ways to practice. This can also provide teachers with a framework to assist their professional development in the era of rapid technological development.

\section{REFERENCES}

Abramo, G., and D'Angelo, C. A. (2011). Evaluating research: from informed peer review to bibliometrics. Scientometrics 87, 499-514. doi: 10.1007/s11192-0110352-7

Angeli, C., and Valanides, N. (2005). Preservice elementary teachers as information and communication technology designers: an instructional systems design model based on an expanded view of pedagogical content knowledge. J. Comput. Assist. Learn. 21, 292-302. doi: 10.1111/j.1365-2729.2005.0 0135.x

Angeli, C., and Valanides, N. (2009). Epistemological and methodological issues for the conceptualization, development, and assessment of ICT-TPCK: advances
At the same time as researchers get a better understanding of these circumstances, they may share their knowledge with teachers, parents, administrators, and other stakeholders to help them change their practices. The findings of this study do not have a direct impact on implications; however, paying closer attention to the context will have a major impact on teaching and learning. Attending to context may bring researchers into contact with a wide range of teachers and students in a variety of settings, enhancing our understanding of teaching with technology across contexts while also providing help and guidance in areas where we are inexperienced (Rosenberg and Koehler, 2015). Finally, our perspective must objectively interpret various bibliographic materials for this research. However, during the last decade, we can see that TPACK has increasingly shifted to more diversified subjects and is even searching for good promotion strategies. We also expect TPACK to be fully exploited in other areas in the future, based on the COVID-19 epidemic.

Finally, as academics who have published scientific studies based on bibliometric analysis, we would want to emphasize the importance of science mapping. This strategy takes advantage of quantitative approaches' accuracy, and it's often surprising how much "numbers explain a rich story." This is due, at least in part, to the approach's concentration on "visualizing relations" between different aspects of the literature. Therefore, after the end of the study, we hope that other academics or databases, such as WOS, will continue with this review study, which could be an alternative for future research. The findings of this fast scoping analysis provided valuable insight into the wide range of publications in the TPACK field that grasp the past and predict the future.

\section{DATA AVAILABILITY STATEMENT}

The raw data supporting the conclusions of this article will be made available by the authors, without undue reservation.

\section{AUTHOR CONTRIBUTIONS}

H-YL and C-YC: conceptualization. C-YC and GW: methodology. H-YL: writing-original draft preparation. H-YL and GW: writing - review and editing. All authors have read and approved the final version of the manuscript, and agree with the order of presentation of the authors.

in technological pedagogical content knowledge (TPCK). Comput. Educ. 52, 154-168. doi: 10.1016/j.compedu.2008.07.006

Aria, M., and Cuccurullo, C. (2017). bibliometrix: an R-tool for comprehensive science mapping analysis. J. Inform. 11, 959-975. doi: 10.1016/j.joi.2017.08.007

Baumert, J., Kunter, M., Blum, W., Brunner, M., Voss, T., Jordan, A., et al. (2010). Teachers' mathematical knowledge, cognitive activation in the classroom, and student progress. Am. Educ. Res. J. 47, 133-180. doi: 10.3102/ 0002831209345157

Briner, R. B., and Denyer, D. (2012). "Systematic review and evidence synthesis as a practice and scholarship tool," in Handbook of evidence-based management: companies, classrooms and research, ed. D. M. Rousseau (Oxford: Oxford University Press), 112-129. doi: 10.1093/oxfordhb/9780199763986.013.0007 
Carpenter, J. P., Rosenberg, J. M., Dousay, T. A., Romero-Hall, E., Trust, T., Kessler, A., et al. (2020). What should teacher educators know about technology? Perspectives and self-assessments. Teach. Teach. Educ. 95:103124. doi: 10.1016/ j.tate.2020.103124

Chai, C. S., Koh, J. H. L., and Tsai, C.-C. (2013). A review of technological pedagogical content knowledge. J. Educ. Technol. Soc. 16, 31-51.

Chen, C. (2006). CiteSpace II: detecting and visualizing emerging trends and transient patterns in scientific literature. J. Am. Soc. Inf. Sci. Technol. 57, 359-377. doi: 10.1002/asi.20317

Cobo, M. J., López-Herrera, A. G., Herrera-Viedma, E., and Herrera, F. (2011). An approach for detecting, quantifying, and visualizing the evolution of a research field: a practical application to the fuzzy sets theory field. J. Inform. 5, 146-166. doi: $10.1016 /$ j.joi.2010.10.002

Cox, S., and Graham, C. R. (2009). Using an elaborated model of the TPACK framework to analyze and depict teacher knowledge. TechTrends 53, 60-69. doi: 10.1007/s11528-009-0327-1

De Battisti, F., Ferrara, A., and Salini, S. (2015). A decade of research in statistics: a topic model approach. Scientometrics 103, 413-433. doi: 10.1007/s11192-0151554-1

Di Blas, N., and Paolini, P. (2016). "Distributed and dynamic TPACK: evidences from a (large) case study," in Paper presented at the Society for Information Technology \& Teacher Education International Conference, eds G. Chamblee and L. Langub (Waynesville, NC USA: Association for the Advancement of Computing in Education (AACE))

Di Blas, N., Paolini, P., Sawaya, S., and Mishra, P. (2014). "Distributed TPACK: going beyond knowledge in the head," in Paper presented at the Society for Information Technology \& Teacher Education International Conference, eds M. Searson and M. N. Ochoa (Jacksonville, Florida, United States: AACE)

Doering, A., Koseoglu, S., Scharber, C., Henrickson, J., and Lanegran, D. (2014). Technology integration in K-12 geography education using TPACK as a conceptual model. J. Geogr. 113, 223-237.

Drugova, E., Zhuravleva, I., Aiusheeva, M., and Grits, D. (2021). Toward a model of learning innovation integration: TPACK-SAMR based analysis of the introduction of a digital learning environment in three Russian universities. Educ. Inf. Technol. 26, 4925-4942. doi: 10.1007/s10639-021-10 514-2

Foulger, T. S., Jin, Y., Mourlam, D. J., and Ebersole, L. (2021). Equitable access to TPACK research: tensions about using social media to disseminate scholarship. Comput. Educ. Open doi: 10.1016/j.caeo.2021.100067

Graham, C. R. (2011). Theoretical considerations for understanding technological pedagogical content knowledge (TPACK). Comput. Educ. 57, 1953-1960. doi: 10.1016/j.compedu.2011.04.010

Harris, J. B., and Hofer, M. J. (2011). Technological pedagogical content knowledge (TPACK) in action: a descriptive study of secondary teachers' curriculum-based, technology-related instructional planning. J. Res. Technol. Educ. 43, 211-229. doi: $10.1080 / 15391523.2011 .10782570$

Herold, B. (2016). Technology in education: an overview. Educ. Week 20, 129-141.

Herring, M. C., Koehler, M. J., and Mishra, P. (2016). "1Introduction to the Second Edition of the TPACK Handbook," in Handbook of technological pedagogical content knowledge (TPACK) for educators, eds M. C. Herring, P. Mishra and M. J. Koehler (Milton Park: Routledge), 11-18.

Hilton, J. T. (2016). A case study of the application of SAMR and TPACK for reflection on technology integration into two social studies classrooms. Soc. Stud. 107, 68-73. doi: 10.4324/9781315771328

Huang, L., and Lajoie, S. P. (2021). Process analysis of teachers' selfregulated learning patterns in technological pedagogical content knowledge development. Comput. Educ. 166:104169. doi: 10.1016/j.compedu.2021.1 04169

Huang, L., Li, S., Poitras, E. G., and Lajoie, S. P. (2021). Latent profiles of selfregulated learning and their impacts on teachers' technology integration. $\mathrm{Br}$. J. Educ. Technol. 52, 695-713. doi: 10.1016/j.compedu.2021.104169

Hughes, J. (2005). The role of teacher knowledge and learning experiences in forming technology-integrated pedagogy. J. Technol. Teach. Educ. 13, 277-302.

Hung, J. L. (2012). Trends of e-learning research from 2000 to 2008: use of text mining and bibliometrics. Br. J. Educ. Technol. 43, 5-16. doi: 10.1111/j.14678535.2010.01144.x

Hussain, A., Fatima, N., and Kumar, D. (2011). Bibliometric analysis of the'Electronic Library'journal (2000-2010). Webology 8:87.
Jaipal-Jamani, K., and Figg, C. (2015). A case study of a TPACK-based approach to teacher professional development: teaching science with blogs. Contemp. Issues Technol. Teach. Educ. 15, 161-200.

Jang, S. J., and Tsai, M. F. (2012). Exploring the TPACK of Taiwanese elementary mathematics and science teachers with respect to use of interactive whiteboards. Comput. Educ. 59, 327-338. doi: 10.1016/j.compedu.2012.02.003

Kevin, W. U. A., Zainab, A. N., and Anuar, N. B. (2017). Bibliometric studies on single journals: a review. Malays. J. Libr. Inf. Sci. 14, 17-55.

Kihoza, P., Zlotnikova, I., Bada, J., and Kalegele, K. (2016). Classroom ICT integration in Tanzania: Opportunities and challenges from the perspectives of TPACK and SAMR models. Int. J. Educ. Dev. ICT 12, 107-128.

Koehler, M. J., Mishra, P., Kereluik, K., Shin, T. S., and Graham, C. R. (2014). "The technological pedagogical content knowledge framework," in Handbook of research on educational communications and technology, eds J. Spector, M. Merrill, J. Elen and M. Bishop (New York, NY: Springer), 101-111. doi: 10.1007/ 978-1-4614-3185-5_9

Koh, J. H. L. (2020). Three approaches for supporting faculty technological pedagogical content knowledge (TPACK) creation through instructional consultation. Br. J. Educ. Technol. 51, 2529-2543. doi: 10.1111/bjet.12930

Lee, M. H., and Tsai, C. C. (2010). Exploring teachers' perceived self efficacy and technological pedagogical content knowledge with respect to educational use of the World Wide Web. Instr. Sci. 38, 1-21. doi: 10.1007/s11251-008-9075-4

Lin, T.-C., Tsai, C.-C., Chai, C. S., and Lee, M.-H. (2013). Identifying science teachers' perceptions of technological pedagogical and content knowledge (TPACK). J. Sci. Educ. Technol. 22, 325-336. doi: 10.1007/s10956-012-9396-6

Lux, N. J., Bangert, A. W., and Whittier, D. B. (2011). The development of an instrument to assess preservice teacher's technological pedagogical content knowledge. J. Educ. Comput. Res. 45, 415-431. doi: 10.2190/ec.45.4.c

Mishra, P. (2019). Considering Contextual Knowledge: the TPACK Diagram Gets an Upgrade. J. Digit. Learn. Teach. Educ. 35, 76-78. doi: 10.1080/21532974. 2019.1588611

Mishra, P., and Koehler, M. J. (2006). Technological pedagogical content knowledge: a framework for teacher knowledge. Teach. Coll. Rec. 108, 10171054. doi: $10.1177 / 016146810610800610$

Niess, M. L. (2005). Preparing teachers to teach science and mathematics with technology: developing a technology pedagogical content knowledge. Teach. Teach. Educ. 21, 509-523. doi: 10.1016/j.tate.2005.03.006

Oberländer, M., Beinicke, A., and Bipp, T. (2020). Digital competencies: a review of the literature and applications in the workplace. Comput. Educ. 146:103752. doi: 10.1016/j.compedu.2019.103752

Owen, K. B., Smith, J., Lubans, D. R., Ng, J. Y., and Lonsdale, C. (2014). Selfdetermined motivation and physical activity in children and adolescents: a systematic review and meta-analysis. Prev. Med. 67, 270-279. doi: 10.1016/j. ypmed.2014.07.033

Özgün-Koca, S. A., Meagher, M., and Edwards, M. T. (2010). Preservice teachers' emerging TPACK in a technology-rich methods class. Math. Educ. 19, 10-20.

Porras-Hernández, L. H., and Salinas-Amescua, B. (2013). Strengthening TPACK: a broader notion of context and the use of teacher's narratives to reveal knowledge construction. J. Educ. Comput. Res. 48, 223-244. doi: 10.2190/ec.48.2.f

Pritchard, A. (1969). Statistical bibliography or bibliometrics. J. Doc. 25, 348-349.

Rosenberg, J. M., and Koehler, M. J. (2015). Context and technological pedagogical content knowledge (TPACK): a systematic review. J. Res. Technol. Educ. 47, 186-210. doi: 10.1080/15391523.2015.1052663

Ryan, T. P., and Woodall, W. H. (2005). The most-cited statistical papers. J. Appl. Stat. 32, 461-474. doi: 10.1080/02664760500079373

Schmid, M., Brianza, E., and Petko, D. (2020). Developing a short assessment instrument for Technological Pedagogical Content Knowledge (TPACK. xs) and comparing the factor structure of an integrative and a transformative model. Comput. Educ. 157:103967. doi: 10.1016/j.compedu.2020.103967

Schmidt, D. A., Baran, E., Thompson, A. D., Mishra, P., Koehler, M. J., and Shin, T. S. (2009). Technological pedagogical content knowledge (TPACK) the development and validation of an assessment instrument for preservice teachers. J. Res. Technol. Educ. 42, 123-149. doi: 10.1080/15391523.2009. 10782544

Shulman, L. (1987). Knowledge and teaching: foundations of the new reform. Harv. Educ. Rev. 57, 1-23. doi: 10.17763/haer.57.1.j463w79r56455411

Shulman, L. S. (1986). Those who understand: knowledge growth in teaching. Educ. Res. 15, 4-14. doi: 10.3102/0013189x015002004 
Small, H. (1973). Co-citation in the scientific literature: a new measure of the relationship between two documents. J. Am. Soc. Inf. Sci. 24, 265-269. doi: 10.1002/asi.4630240406

Soler-Costa, R., Moreno-Guerrero, A.-J., López-Belmonte, J., and Marín-Marín, J.A. (2021). Co-Word Analysis and Academic Performance of the Term TPACK in Web of Science. Sustainability 13:1481. doi: 10.3390/su13031481

Tsay, M.-Y. (2011). A bibliometric analysis and comparison on three information science journals: JASIST, IPM, JOD, 1998-2008. Scientometrics 89, 591-606. doi: 10.1007/s11192-011-0460-4

Tseng, F.-C., and Kuo, F.-Y. (2014). A study of social participation and knowledge sharing in the teachers' online professional community of practice. Comput. Educ. 72, 37-47. doi: 10.1016/j.compedu.2013.10.005

Tunjera, N., and Chigona, A. (2020). Teacher Educators' appropriation of TPACKSAMR models for 21 st century pre-service teacher preparation. Int. J. Inf. Commun. Technol. Educ. 16, 126-140. doi: 10.4018/IJICTE.2020070110

Van Eck, N. J., and Waltman, L. (2010). Software survey: VOSviewer, a computer program for bibliometric mapping. Scientometrics 84, 523-538. doi: 10.1007/ s11192-009-0146-3

Van Eck, N. J., and Waltman, L. (2017). Citation-based clustering of publications using CitNetExplorer and VOSviewer. Scientometrics 111, 1053-1070. doi: 10. 1007/s11192-017-2300-7

Van Laar, E., Van Deursen, A. J., Van Dijk, J. A., and De Haan, J. (2017). The relation between 21 st-century skills and digital skills: a systematic literature review. Comput. Hum. Behav. 72, 577-588. doi: 10.1016/j.chb.2017. 03.010

Voogt, J., Fisser, P., Pareja Roblin, N., Tondeur, J., and van Braak, J. (2013). Technological pedagogical content knowledge-a review of the literature. J. Comput. Assist. Learn. 29, 109-121. doi: 10.1111/j.1365-2729.2012.00 487.x

Wang, W., Schmidt-Crawford, D., and Jin, Y. (2018). Preservice teachers' TPACK development: a review of literature. J. Digit. Learn. Teach. Educ. 34, 234-258. doi: 10.1080/21532974.2018.1498039

Willermark, S. (2018). Technological pedagogical and content knowledge: a review of empirical studies published from 2011 to 2016. J. Educ. Comput. Res. 56, 315-343. doi: 10.1177/0735633117713114
Wu, Y.-T. (2013). Research trends in technological pedagogical content knowledge (TPACK) research: a review of empirical studies published in selected journals from 2002 to 2011. Br. J. Educ. Technol. 44, E73-E76.

Yeh, Y.-F., Chan, K. K. H., and Hsu, Y.-S. (2021). Toward a framework that connects individual TPACK and collective TPACK: a systematic review of TPACK studies investigating teacher collaborative discourse in the learning by design process. Comput. Educ. 171:104238. doi: 10.1016/j.compedu.2021. 104238

Yeh, Y. F., Hsu, Y. S., Wu, H. K., Hwang, F. K., and Lin, T. C. (2014). Developing and validating technological pedagogical content knowledgepractical (TPACK-practical) through the D elphi survey technique. Br. J. Educ. Technol. 45, 707-722. doi: 10.1111/bjet.12078

Yurtseven Avci, Z., O’Dwyer, L. M., and Lawson, J. (2020). Designing effective professional development for technology integration in schools. J. Comput. Assist. Learn. 36, 160-177. doi: 10.1111/jcal.12394

Zupic, I., and Čater, T. (2015). Bibliometric methods in management and organization. Organ. Res. Methods 18, 429-472. doi: 10.1177/ 1094428114562629

Conflict of Interest: The authors declare that the research was conducted in the absence of any commercial or financial relationships that could be construed as a potential conflict of interest.

Publisher's Note: All claims expressed in this article are solely those of the authors and do not necessarily represent those of their affiliated organizations, or those of the publisher, the editors and the reviewers. Any product that may be evaluated in this article, or claim that may be made by its manufacturer, is not guaranteed or endorsed by the publisher.

Copyright (c) 2022 Lee, Chung and Wei. This is an open-access article distributed under the terms of the Creative Commons Attribution License (CC BY). The use, distribution or reproduction in other forums is permitted, provided the original author(s) and the copyright owner(s) are credited and that the original publication in this journal is cited, in accordance with accepted academic practice. No use, distribution or reproduction is permitted which does not comply with these terms. 